\title{
A Via Sacra da Hanseníase de Veganin
}

\author{
Veganin's Leprosy Via Sacra
}

La Via Sacra de la Lepra de Vaganin

\section{Nadja Cristiane Lappann Boti', Kiane Aparecida Aquino' \\ 'Pontifícia Universitária Católica. Betim, MG}

Submissão: 28/08/2008

Aprovação: 15/10/2008

\section{RESUMO}

Foi realizada pesquisa histórica com análise documental e história oral objetivando descrever a biografia e analisar a pintura de Veganin. Luiz Carlos de Souza nasceu em 1950 em Aimorés (MG) e aos 16 anos foi trabalhar na enfermagem na Santa Casa de Misericórdia de Belo Horizonte. Com 20 anos foi internado na Colônia Santa Isabel (MG) e passou a ser conhecido como "Veganin". Na Colônia trabalhou na enfermagem, marcenaria e pintura. Pintou no estilo da Pop Art os Quadros da Via Sacra onde mostra a Paixão de Cristo com originalidade e crítica social. Nos Quadros apresenta sua resiliência frente à hanseníase e ao tratamento. Faleceu na Colônia Santa Fé (MG) em 1997. Descritores: Hanseníase; Enfermagem; Pesquisa Qualitativa.

\section{ABSTRACT}

Historical research was carried out with documentary analysis and oral history aiming at describing the biography and reviewing the painting of Veganin. Luiz Carlos de Souza was born in 1950 in Aimorés (MG) and at age of 16 years he was working in nursing at the Santa Casa de Misericórdia in Belo Horizonte. With 20 years he was hospitalized in Colônia Santa Isabel and is now known as "Veganin". In Colônia worked in nursing, carpentry and painting. He painted in the style of Pop Art the tables's Via Sacra where shows the Passion of Christ with originality and social criticism. In his paintings he presents his resilience front of the disease and treatment. Died in Colônia Santa Fé (MG) in 1997.

Descriptors: Hansen's disease; Nursing; Qualitative research.

\section{RESUMEN}

La investigación histórica se llevó a cabo con análisis documental y la historia oral con el objetivo de describir la biografía y la revisión de la pintura de Veganin. Luiz Carlos de Souza nació en 1950 en Aimorés (MG) y a la edad de 16 años estaba trabajando en enfermería en la Santa Casa de Misericordia de Belo Horizonte. Con 20 años fue hospitalizado en Colônia Santa Isabel y Que ahora se conoce como "Veganin". En Colônia trabajado en enfermería, carpintería y pintura. Pintó en el estilo Pop Art de los cuadros del Vía Sacra, donde se muestra la Pasión de Cristo con la originalidad y la crítica social.Los cuadros muestran su resistencia en relación la enfermedad y el tratamiento. Muerto en Colônia Santa Fé (MG) en 1997.

Descriptores: Lepra; Enfermería; Pesquisa cualitativa. 


\section{INTRODUÇÃO}

A imagem social da hanseníase é histórica. O desenvolvimento da ciência não foi suficiente para mudar a resposta de medo e preconceito em relação à doença, apesar de Armauer Hansen, em fins do século XIX, descobrir o agente causador da doença, comprovando o caráter infecto-contagioso e anulando a idéia de hereditariedade, pecado ou castigo, ainda assim, surge a teoria de Que o isolamento do doente eliminaria o mal, incentivando a adoção do modelo de tratamento baseado no cerceamento da liberdade em grandes instituições de isolamento ${ }^{(1)}$. Até hoje o impacto provocado pela doença interfere no cotidiano dos indivíduos, Que têm na hanseníase, a ameaça constante do preconceito marcado por sofrimento, abandono, deformidades e problemas psicossociais ${ }^{(2)}$.

A Colônia Santa Isabel, localizada em Betim (MG), foi criada com a política sanitária de Oswaldo Cruz sendo inaugurada em 1931. Na época representou exemplo notório da política sanitarista adotada no país direcionada para a erradicação das doenças contagiosas. Seu desenho urbano é característico de colônias desta natureza com medidas sanitaristas de "cunho profilático", na verdade segregador ${ }^{(3)}$. Até metade da década de 1980 funcionava restritamente aos doentes e seus familiares, agentes de saúde e religiosos.

Esta Colônia apresenta histórias de vidas Que tiveram a estigmatização como marca social, entre elas encontramos a biografia de Luiz Carlos Souza acometido pela hanseníase. Foi morador, por décadas, dos pavilhões e casas da Colônia, onde se tornou conhecido como "Luiz Veganin". Trabalhou na área da Enfermagem e era considerado artista nato pela comunidade de hansenianos e nãohansenianos moradores da Colônia Santa Isabel e entorno. No final da década de 1980, a pedido do Frei Chico, pároco da Matriz de Santa Isabel, pintou a Via Sacra, conjunto de Quatorze Quadros representando a Paixão de Cristo. A obra foi finalizada em 1991 e encontra-se no interior da Matriz de Santa Isabel. Em 1994, ele mudou-se para a Colônia Santa Fé, localizada em Três Corações (MG), onde faleceu.

Esta pesquisa visa descrever a biografia de Luiz Veganin e investigar os significados da pintura do $5^{\circ}$ Quadro da sua Via Sacra. Entendemos a relevância desta investigação pela trajetória histórica da hanseníase e suas conseqüências sociais, físicas e psíquicas e pelo processo de segregação e exclusão que acompanha o histórico da mais antiga colônia de Minas Gerais.

\section{METODOLOGIA}

Para alcançarmos os objetivos propostos realizamos investigação histórica sobre Luiz Veganin e sua Via Sacra, reconhecendo Que é tarefa do historiador localizar, avaliar e sintetizar sistemática e objetivamente as provas, para estabelecer os fatos e obter conclusões referentes aos acontecimentos do passado ${ }^{(4)}$. Dividimos a investigação em duas partes, a primeira refere-se à biografia de Luiz Veganin; e a segunda, à iconografia dos euadros da Via Sacra. Empregamos como instrumento de coleta de dados, a entrevista e busca de documentos e como referencial metodológico, a análise documental e a história oral temática.

A análise documental possibilita o conhecimento do passado ${ }^{(4)}$. Utilizamos como documentos: ficha de identificação, fotografias, cartas, recibos, Jornal Voz de Betim, Jornal Estado de Minas, publicações do MORHAN do acervo do Memorial José Avelino localizado na Colônia Santa Isabel.

Realizamos a história oral temática através de entrevistas semiestruturas com Quatorze sujeitos Que conviveram com Luiz Veganin. Este método baseia-se no depoimento oral e gravado onde o entrevistado é o ator social/testemunha de fatos relevantes para a compreensão do objeto de estudo, inclusive para a obtenção de relatos sobre fatos negligenciados pela documentação escrita ${ }^{(4)}$. Entre os entrevistados encontram-se amigos, colegas de trabalho, familiares, ex-namorada e ex-médico; moradores da Colônia ou do entorno (ex-hansenianos e não-hansenianos), exceto o familiar Que mora na cidade de Vitória (Espírito Santo). Realizamos as entrevistas no interior da Matriz de Santa Isabel.

Entendemos Que a história oral temática é capaz de resgatar a identidade do sujeito ${ }^{(5)}$, pois a palavra através da narrativa da história permite revelar Quem foi Luiz Veganin e os significados da sua obra. Para tal as entrevistas tiveram como Questões norteadoras: 1) O Que você sabe sobre Luiz Veganin? e 2) O Que você sabe sobre os Quadros da Via Sacra de Luiz Veganin? Para investigarmos os significados da pintura dos euadros da Via Sacra utilizamos a análise iconográfica. A iconografia é o ramo da história da arte Que trata do tema ou mensagem das obras de arte em contraposição à sua forma ${ }^{(6)}$.

Ressaltamos Que os preceitos éticos da Resolução 196/1996 foram respeitados: o projeto de pesQuisa foi aprovado pelo CEP da PUC Minas (CAAE 0034.0.213.000-07) e autorizado pela coordenação do Curso de Enfermagem e pelo presidente do MORHAN; e os entrevistados manifestaram anuência através da assinatura do Termo de Consentimento Livre e Esclarecido.

\section{RESULTADOS E DISCUSSÃO}

\section{Biografia de Luiz Veganin}

Luiz Carlos de Souza nasceu em Aimorés (MG) no dia 28 de fevereiro de 1950. Aos nove anos foi morar com seus avós maternos Leonídia de Souza Nunes e Elpídio de Souza Nunes, pois sua mãe, Abigaíu Souza Nunes, viúva casou-se novamente com Lionou Guilherme de Souza. O avô de Luiz Carlos trabalhava como maquinista da Companhia Vale do Rio Doce e sua avó, dona do lar. Foi a avó materna Que cuidou de Luiz Carlos, devido o segundo casamento da sua mãe e posteriormente, ela veio a falecer, ficando Luiz Carlos órfão.

Aos 16 anos de idade saiu da casa dos seus avós em Aimorés e foi trabalhar como voluntário na Enfermagem na Santa Casa de Misericórdia de Belo Horizonte. Trabalhou na Santa Casa durante Quatro anos onde recebeu o diagnóstico de hanseníase e a indicação de tratamento na Colônia Santa Isabel. Fisicamente era um homem moreno, magro, de estatura baixa, com cabelo liso e vozeirão.

No dia 10 de agosto de 1970, com 20 anos de idade, foi internado na Colônia Santa Isabel. Nesta época sofreu os temores e angústias da doença receando "não poder mais fazer nada e pedaços caírem", chegando a ficar numa cadeira de rodas, sem Querer andar, até entrevar as pernas. Permaneceu no pavilhão Gustavo Capanema durante 8 anos em função da paralisia dos membros inferiores devido a nevrite. Quando Luiz Carlos chegou a Colônia já se encontrava na transição do modelo de assistência, porém o processo de desinstitucionalização durou 6 anos, de 1976 a $1982^{(7)}$. Sabemos historicamente Que as colônias no Brasil foram construídas para abrigarem grande 
número de doentes tornado-se verdadeiras cidades ${ }^{(1)}$.

No cotidiano das colônias os doentes conviviam com a angústia diária de verem seus corpos sendo "mutilados" pela doença Que, à época, não tinha cura. Com a internação Luiz Carlos sofreu o preconceito e o estigma familiar em relação à doença associado aos efeitos do isolamento social. Como era a realidade da maioria dos internos, ele não tinha contato pessoal com a família, nem através de cartas, devido ao medo dos familiares em relação a transmissão da hanseníase pelo papel.

Na Colônia Santa Isabel, Luiz Carlos de Souza, passou a ser reconhecido como "Veganin". Esta nova identidade ocorreu devido à automedicação com um remédio ${ }^{a}$ com o mesmo nome Que utilizava em função das suas dores de nevrite. Mas também porque depois de sua saída do pavilhão retornou ao trabalho na Enfermagem e então era o responsável em administrar esta medicação aos outros hansenianos internos na Colônia.

Luiz Carlos de Souza ao ser identificado como Veganin exemplifica a perda da identidade Que ocorre nas instituições totais ${ }^{(8)}$. Essa nova identidade é a marca da doença revelada, neste caso, através do seu tratamento. A construção dessa nova identidade mostra a violência das políticas sanitárias adotadas para controle da doença e legitimada pelas crenças e valores culturais. A história revela Que a hanseníase produz perda física e social, mas como visto, também de identidade. Entendemos Que a perda da identidade do próprio nome, Luiz Carlos de Souza por Luiz Veganin, evidencia a grande mutilação no Eu ocorrida nas instituições totais ${ }^{(8)}$. A nova identidade somente viria no interior da Colônia, onde todos se reconheceriam como iguais diante do infortúnio da doença ${ }^{(1)}$.

Sabemos historicamente Que a hanseníase é permeada por estigmas e preconceitos sendo por décadas tratada exclusivamente com o isolamento compulsório em colônias. Nesses locais o estigma, o medo e o preconceito eram fatores negativos inclusive na contratação de recursos humanos assim, os próprios internos se tornavam funcionários e cuidadores dentro destas instituições ${ }^{(1)}$.

Dessa forma, os próprios doentes se tornavam cuidadores e trabalhadores da Enfermagem, como também foi o caso de Veganin na Colônia Santa Isabel. A história coloca Que em geral os internos não tinham escolha, eram simplesmente direcionados para os serviços e obrigados a trabalharem para se manterem financeiramente ou então "punidos" com castigos caso não obedecessem às normas impostas pelas irmãs de caridade, coordenadoras da Colônia ${ }^{(9)}$. Também havia familiares de hansenianos internos na Colônia Que se tornaram atendentes de Enfermagem, onde "doavam" seu trabalho a fim de oferecer conforto aos doentes no pavilhão e lá ficaram até serem contratados ${ }^{(10)}$.

Depois do pavilhão Gustavo Capanema, Luiz Veganin passou a morar num "galpão" atrás do Pavilhão Maria Luiza Machado Vieira, conhecido como pavilhão dos meninos. Neste galpão, Que era uma fábrica de tecido infantil Que nunca funcionou, ele morou durante 14 anos e foi o local onde trabalhou também como marceneiro e artista.

Neste galpão Luiz Veganin arQuitetou sua casa e seu local de trabalho. Era um espaço improvisado, sem infra-estrutura e divisão onde havia Quarto, cozinha, banheiro, marcenaria e uma área de leitura. Apesar de localizar-se dentro da área da Colônia, ele tinha

${ }^{a}$ O remédio Veganin era composto por aspirina, paracetamol e fosfato de codeína. autonomia e independência, pois era onde dormia, preparava sua comida no fogão à lenha, recebia seus amigos Que também moravam na Colônia Santa Isabel e também trabalhava com a marcenaria e a pintura.

Luiz Veganin era um homem tempestivo e sistemático. Sua tempestividade se revelava na labilidade emocional assim, "hora tava pro pé, hora tava pra cabeça". Como pessoa ensimesmada apresentava-se de forma introspectiva, calada e reservada, em geral ficava isolado no galpão trabalhando ou lendo ou no hospital trabalhando na Enfermagem. Era uma pessoa modesta, humilde e desprendida materialmente. Associado a essas características também era uma sujeito confiável e fiel aos amigos e no seu círculo de amizade era traneüilo e comunicativo.

Como norma da Colônia todos os relacionamentos amorosos eram impedidos pelas irmãs do Monte Calvário que administravam a instituição, apesar disto Veganin cultivou seus namoros. No primeiro relacionamento foi um homem ciumento e desejava casar-se, após esta desilusão desistiu da idéia do casamento e de relacionamentos, apesar de ter tido outras paixões, tornaram-se superficiais.

Era um sujeito perspicaz assim, apesar de ter cursado até a $4^{\mathrm{a}}$ série do ensino fundamental era autodidata e adorava ler. Sua leitura compreendia desde as teorias Marxistas, Filosofia, Literatura, Psicologia, além de histórias em Quadrinho, como Donald, Patinhas, e especialmente Brucutu e revistas semanais brasileiras, como Veja e Manchete. Leu entre os autores: Platão, Freud, Jung, Gandhi, Marx, Leo Huberman, Machado de Assis e Guimarães Rosa; entre os livros: Nós também somos gente de Orestes Dinis, Manifesto do Partido Comunista de Karl Marx e Friedrich Engels, Vida de Lênin de Louis Fischer, Tao da Física de Fritjof Capra e o Dicionário de Ciências Sociais da Fundação Getúlio Vargas.

Luiz Veganin apesar de ter sido internado na Colônia Santa Isabel com 20 anos de idade, ter passado 8 anos dentro do Pavilhão Gustavo Capanema, apresenta peculiaridades no seu estilo de vida. Entre estas particularidades vemos seu estilo "urtigão", assim como eremita ficava muito tempo solitariamente e tinha dificuldade com regra e horário. Tinha gosto pela culinária, dizendo Que se deveria comer devagar pra saborear os alimentos; freqüentava o Cine-Teatro Glória e o campo de futebol da Colônia para assistir filmes e jogos de futebol. Assim, com seu desejo de liberdade e autonomia ele preservou sua personalidade, algo difícil dentro de uma colônia para hanseniano.

Em relação à aprendizagem da marcenaria iniciou, Quando criança, com o tio Benerval Que morava próximo a casa dos seus avós em Aimorés. Como marceneiro fez vários móveis e objetos de ornamentação, entre eles encontramos na Matriz de Santa Isabel uma escultura de mãos em prece. Na pintura, não teve professor, e acreditava ter o dom de trabalhar com arte, além da arte de cuidar da Enfermagem.

Veganin não aceitava a doença e a carga social imputada pelo estigma e tratamento na Colônia e por isso, muitas vezes mostravase revoltado e inseguro. Devido seus temores e angústia, era extremamente receoso em relação à sua vida social e principalmente seu trabalho artístico.

Veganin não aceitava ser considerado artista: sou um cidadão, igual a você mesmo, eu não sou artista nenhum. Quando nomeado de artista ameaçava ir embora apesar do reconhecimento de sua habilidade artística pelos amigos e por aqueles que conheciam seus móveis e pinturas. Inúmeras vezes foi seu maior crítico em relação à 
pintura e Quando não gostava, pisava e sapateava sobre a tela; às vezes achava Que o ideal era tão grande e distante Que então desesperava.

Durante 5 anos pintou os Quadros da Via Sacra sendo entregue à Matriz de Santa Isabel na Quaresma de 1993. Esse trabalho contou com a orientação direta de frei Francisco Van der Poel, conhecido como frei Chico. Os 14 Quadros da Via Sacra foram financiados pelo São Bernadinus College, de Heerlen, na Holanda, terra natal de Dom Frei Diogo Reesink, ex-pároco de Santa Isabel ${ }^{(1)}$. Todos os Quadros são retangulares medindo $84 \times 60 \mathrm{~cm}$ e encontram-se na Matriz.

Pintou os quadros da Via Sacra durante o período de 1987 a 1992. Em 1988, Dom Frei Diogo Reesink em carta de comemoração do jubileu e descrição do "leprosário" de Betim solicita ajuda financeira para a realização dos Quadros da Via Sacra de Veganin: Quanto ao lado financeiro desse projeto, Luiz precisa para sua própria manutenção e custo de materiais 1.500 florins. Veganin nessa carta é apresentando como: Luiz, 35 anos paciente com lepra e artista ${ }^{(12)}$. Ele além de não aceitar ser identificado como artista também não admitia a vinculação entre sua produção artística e a hanseníase. Veganin acreditava Que teria realizado a Via Sacra independente de ser hanseniano: pelejo para ser um artesão, não sou um artista leproso, não sou Aleijadinho. Esta posição de Veganin se acentuou, principalmente, depois da finalização dos Quadros da Via Sacra.

Veganin pintou os Quadros da Via Sacra no galpão onde morava. Fazia os esboços com lápis de pedreiro diretamente sobre a tela e somente pintava Quando estava sozinho. Pela pintura da Via Sacra Veganin recebeu pagamento de Dom Frei Diogo Reesink e frei Francisco Van Der Poel. Sendo o primeiro pagamento em fevereiro de 1987, totalizando $\mathrm{C} z \$ 2.000,00$; e o último, em março de 1992, de Cr\$96.500,00. Quando convertemos os pagamentos em salário mínimo vigentes à época (moedas da época) encontramos Que ele recebeu o total de 99,46 salários mínimos para pintar os Quadros da Via Sacra.

Durante a pintura da Via Sacra foram raras as visitas dos amigos, além de frei Chico, recebia a visita de 5 canários da terra e 2 sabiás ${ }^{(13)}$. Segundo frei Chico, para Veganin pintar a Via Sacra foi uma Questão de vida ou morte, pois temia morrer sem concluí-la e gostaria de deixar alguma coisa nessa vida. Para Veganin eram obras do acaso onde passado e presentes Que representam minha vida estão presentes $^{(1)}$. Para frei Dom Diogo Reesink as estações da Via Sacra de Luiz Veganin eram um apoio para liberdade, justiça e para um futuro melhor Que visava ligar o sofrimento dos pacientes com lepra, do povo da América Latina com o sofrimento de Cristo, assim dando esperança aos moradores de Santa Isabel ${ }^{(12)}$.

Após o término da pintura da Via Sacra, em 1992, Veganin se refugiou indo morar na Colônia Santa Fé em Três Corações (MG). No período de 1992 a 1997, apesar da distância, recebia a visita dos amigos da Colônia Santa Isabel Quando, então fazia hemodiálise e também escrevia cartas aos seus amigos. Numa dessas cartas, Veganin revelava o desejo de retornar à atividade laboral e artística Quando solicita ao amigo sua antiga plaina.

Veganin tinha hansen virshowiana e no dia $1^{\circ}$ de outubro de 1997 faleceu na Colônia Santa Fé devido à amiloidose secundária Que é uma séria complicação da hanseníase, principalmente da virchoviana $^{(14)}$. A amiloidose secundária geralmente envolve o fígado, baço e rins. O rim Quando acometido freeüentemente evolui para a insuficiência deste órgão ${ }^{(14)}$. Após sua morte, os amigos custearam a busca do seu corpo em Três Corações para ser enterrado no cemitério "Reino das Rosas" da Colônia Santa Isabel, em Betim.

\section{Estação da Via Sacra de Luiz Veganin}

A Via Crucis é o trajeto seguido por Cristo carregando a cruz do Pretório de Pilatos até o Calvário. O exercício da Via Sacra consiste em Que os fiéis percorram mentalmente a caminhada de Cristo a carregar a cruz, meditando sobre a Paixão de Cristo. Compreende 14 estações, cada uma das Quais apresenta uma cena da Paixão. A Via Sacra de Veganim mostra os passos de Cristo de forma original com humor e crítica social, política e econômica no estilo artístico da Pop Art. Retrata moradores da Colônia mesclando com personalidades históricas, mitológicas e de história em Quadrinhos apresenta com cores a hanseníase e o tratamento nas colônias e os problemas sociais, políticos, éticos, religiosos, ambientais e econômicos presentes no contexto nacional e da comunidade de Santa Isabel.

O movimento Pop Art tem como principal objetivo a crítica irônica do bombardeamento da sociedade pelos objetos de consumo ${ }^{(15)}$. Identificamos na Via Sacra de Veganin, personagens de estórias em Quadrinhos, da história história nacional, do cotidiano da Colônia Santa Isabel e da cultura popular. A mídia e a publicidade são os temas favoritos da Pop Arte, Que muitas vezes celebravam espirituosamente a sociedade de consumo ${ }^{(15)}$. Nesse sentido encontramos como eneuadres de pintura da Via Sacra de Veganin; a representação de palco (Estações I e X), a televisão (Estação III) e a janela (Estação II). Além dos enquadres também localizamos como personagens homens Que filmam, fotografam e televisionam a Paixão de Cristo. As telas retratam os passos de Cristo personificado como hanseniano, índio, negro, menor abandonado ou operário Que carrega a cruz por paisagens insólitas. Em todos os Quadros, Cristo é cercado por símbolos da cultura universal como Maria, representada como "Mãe Terra", mas também por diversos personagens de histórias em Quadrinhos, cowboys, generais e personalidades históricas e da própria Colônia Santa Isabel. Nas suas pinturas surgem figuras típicas de Betim; ao invés de soldados romanos, soldados da Polícia Militar; ao invés de edificações romanas, a escola da Colônia e a própria Matriz.

É na V Estação da Via Sacra Que Simão de Cirineu é forçado a levar a cruz de Cristo, pois a cruz pesa-lhe demasiadamente sobre os ombros e ele está próximo de sucumbir às hemorragias ${ }^{(16)}$. Nesse momento crítico Simão Cireneu, camponês rude Que passa pelo caminho, é agarrado pelos soldados e obrigado a carregar a cruz assim, fez-se solidário no esforço e na pena ${ }^{(17)}$.

$\mathrm{O}$ homem acumula conhecimento e informações à medida Que estas lhe são apresentadas dentro de um processo dinâmico, tratando-se de uma atividade Que o sujeito constrói a realidade, privilegiando tanto a relação entre o individual e o social Quanto o pensamento e a atividade ${ }^{(18)}$. Os discursos e atitudes do sujeito nos levam a identificar as representações de cada um sobre a sua própria doença. A hanseníase é enfermidade Que, sob o ponto de vista cultural, remete o imaginário das pessoas a símbolos negativos em diversas sociedades, inclusive a brasileira, e, portanto esta doença possibilita melhor compreensão dos inevitáveis efeitos físico, psicológico, social e cultural ${ }^{(18)}$. Por outro lado, sob o ponto de vista médico, a doença conta com tratamento e cura obtendo-se, portanto confluência biológica e cultural. 
Na V Estação da Via Sacra, Veganin pinta no primeiro plano, ao centro, Simão de Cirineu, um negro forte com os pés rachados Que ajuda Cristo carregar a cruz. Na cruz vemos cartelas de medicamentos, ambulância, maca, seringa, cama de hospital, faixas, gazes, algodão, sulfona e água oxigenada (base de remédio para hanseníase), ampolas, próteses e muleta. Neste Quadro Simão de Cirineu carrega a cruz com o tratamento da hanseníase vivido na época na Colônia Santa Isabel revelando Que o próprio tratamento da hanseníase se tornou a cruz para o hanseniano: "esse homem sem blusa carregando a cruz era a gente na época. A gente trabalhava pra nós mesmos. A gente carregava a cruz sem calçado". Uma cruz pesada infligida aos hansenianos como a Que impuseram aos ombros de Cristo, cruz entendida como a expressão de condenação por parte dos homens ${ }^{(17)}$.

Neste Quadro encontramos Cristo como hanseniano com as mãos em garra. Veganin sabia eneuanto hanseniano e profissional da Enfermagem sobre as características da doença e principalmente que envolve concretamente incapacidade física Que obstaculizam as Questões laborativas e seguem para uma situação de exclusão e estigma ${ }^{(18)}$. Também representa a hanseníase Que compõe o senso comum das pessoas e encontra-se referendado na representação tradicional, de cunho histórico, da "lepra”. Esta denúncia pictórica da apresentação de Cristo evidencia Que a "lepra” é uma doença Que, culturalmente, remete ao imaginário com símbolos negativos ${ }^{(18)}$. $\mathrm{E}$ também Que não vemos mudanças com relação à representação da doença apesar dos investimentos públicos destinados a divulgação e informação da nova terminologia da doença, adotada desde a década de $1970^{(19)}$.

O portador de Hanseníase se preocupa com a aparência, pois essa tem impacto negativo no convívio familiar e social, na autorejeição e na dificuldade para aderir ao tratamento. Em nossa cultura, os padrões físicos de beleza são geralmente acoplados aos padrões morais, assim o belo é vinculado com bom e os padrões definitórios de feio induzem à idéia de mau ${ }^{(2)}$. Até hoje o impacto provocado pela doença interfere no cotidiano dos indivíduos, Que tem na hanseníase, a ameaça constante do preconceito marcado por sofrimento, abandono, deformidades e problemas psicossociais Que, inevitavelmente, acabam por ocorrer na ordem social ${ }^{(2)}$.

Junto a Cristo vemos o médico Orestes Diniz, primeiro diretor da Colônia Santa Isabel, e as irmãs de caridade do Monte Calvário. As irmãs do Monte Calvário moravam na colônia e cuidavam dos hansenianos e da administração. Elas selecionavam os doentes internos para os mais diversos trabalhos necessários para o funcionamento da Colônia, inclusive para a prestação de cuidados de Enfermagem $^{(20)}$.

Olhando Simão de Cirineu carregando a cruz encontramos um soldado romano também, como Cristo, com as marcas físicas da hanseníase. Como cenário temos a Colônia Santa Isabel ${ }^{\mathrm{b}}$ com a sua Igreja Matriz, o rio Paraopeba (afluente rio São Francisco e Que atravessa a Colônia), o portal e o cemitério "Reino das Rosas" e o Dureza (antigo alcoolista e morador da Colônia).

\footnotetext{
${ }^{b}$ Veganin em outras estações da Via Sacra também pintou a arQuitetura e vida cotidiana da comunidade da Colônia Santa Isabel, entre eles destacamos: o monumento do Padre Damião localizado na praça em frente a Igreja (Estação III), a "jardineira do Ioão Pipoca", ônibus que fazia o transporte dos moradores doentes da Colônia para Belo Horizonte (Estação VIII), o cemitério, a casa paroquial e demais casas da Colônia (Estação X), moradores da Colônia (Estação XI) e objetos de uso pessoal, como sua lupa, livro e mala (Estação XII).
}

O portal foi construído, em estilo espanhol e é a antiga entrada da Colônia, hoje desativada. Trata-se de uma arquitetura com ornamentação clássica, destacando a inscrição "Hicmane binus potime" (Aqui estaremos bem). Esse portal, durante anos foi a única entrada para a Colônia, tinha duas guaritas e correntes Que separava a entrada e saída, a sociedade e os pavilhões, proibindo o contato dos moradores - hansenianos e seus familiares - com a sociedade ${ }^{(21)}$. Em 1997, o portal foi tombado como Patrimônio Histórico e Cultural de Betim ${ }^{(21)}$, por ser um marco Que testemunha a concepção inicial do tratamento ${ }^{(11)}$ Que apesar de ter originalmente a intenção de ser terapêutica se tornou um aviltamento a cidadania e a ética. Esse sentimento é expresso por Luiz Veganin como abandono, medo e revolta vividos durante sua internação na Colônia.

Também vemos o muro e o cavalo de Tróiac junto ao cenário da Colônia Santa Isabel. Aqui Veganin ironicamente revela o "presente de grego" Que se tornaram as colônias para os hansenianos. Sabemos Que historicamente as colônias tinham como prática o confinamento compulsório em função das idéias fantasiosas acerca da doença, aliado às deformidades físicas do seu estágio avançado Que instituíram o sentimento coletivo de medo e repulsa. A sociedade frente à possibilidade de contágio da doença e perda da saúde, estética e beleza acabaram legitimando o uso do afastamento institucionalizado. O doente não tinha alternativa para seu tratamento senão submeter-se ao confinamento na colônia, por isso Veganin coloca Cristo hanseniano chegando à Colônia com sua mala. Apesar de outras formas de tratamento, o asilamento era considerado o mais eficaz de obter seus fins, ainda Que representasse a "morte" para o "leproso" e sua família( ${ }^{(1)}$. Ainda, nesta estação, vemos o símbolo da ditadura: "Brasil: ame-o ou deixe-o", assim Veganin faz uma crítica à política pública de segregação e exclusão compulsória do tratamento da hanseníase como análogo à ditadura e repressão militar.

No estudo da trajetória da "lepra" verificamos Que parte da visão medieval acerca da doença e do doente chegou até o século XX, e assim apesar do avanço da ciência, medidas de exclusão continuaram a ser praticadas em nome da defesa do bem estar coletivo. Mesmo após a descoberta da terapêutica eficaz contra a doença ${ }^{\mathrm{d}}$, medidas de segregação, exclusão e violência continuaram a ser praticadas com os doentes e seus familiares ${ }^{(1)}$.

As colônias construídas para abrigarem grande número de doentes, tornaram-se verdadeiras cidades, com cemitério, cinema, lanchonetes, ruas, times de futebol e inclusive prefeito e moeda própria ${ }^{(19)}$. Em seu cotidiano, os doentes conviviam com a angústia diária de verem seus corpos sendo "mutilados" pela doença Que, na época, não tinha cura. Em geral foram construídas em locais de difícil acesso, com muros altos, cercas de arames, portões trancados e vigilância para capturar fugitivos e novos doentes ${ }^{(19)}$. A Colônia Santa Isabel foi construída à margem do rio Paraopeba e na época da construção tinha estação ferroviária, infra-estrutura avançada, além

\footnotetext{
c Foi um grande cavalo de madeira deixado junto às muralhas de Tróia Que num primeiro momento seria um presente como sinal de rendição do exército inimigo, mas na verdade era um cavalo com o seu interior oco que abrigava soldados gregos para destruir e incendiar Tróia.

¿ $O$ ano de 1943 representou o marco revolucionário na trajetória da hanseníase, pois foi descoberto o tratamento através das sulfonas. Com este tratamento, em poucos meses, o doente tinha sua baciloscopia negativa, significando perda da sua condição de infectante e, portanto, deixava de representar ameaça à coletividade podendo, inclusive, conviver em sociedade.
} 
de áreas de lazer coletivo, como o Cine-Teatro Glória e os clubes recreativos $^{(21)}$. Refletindo a religiosidade, também foi construída a Matriz de Santa Isabel. Até metade da década de 1980, a Colônia funcionava restritamente aos doentes e seus familiares, agentes de saúde e religiosos.

Sabemos Que a resiliência não é sinônimo de resistência, mas é o fenômeno de crescimento ou transformação resultante do enfrentamento. Existência de uma liberdade interior Que possibilita ao ser humano permanecer sendo pessoa humana, conservando sua dignidade mesmo frente ao insuportável ${ }^{(22)}$. Assim, Veganin diante das condições adversas da vivência da hanseníase e do tratamento, Que colocava em Questão a sua sobrevivência, integridade física e psíeuica, conseguiu recriar a base estrutural de sua existência, expandir a sua liberdade interior e com a arte e criatividade a transformou em fator de crescimento e desenvolvimento pessoal.

\section{CONCLUSÃO}

O estilo de vida e a composição dos Quadros de Veganin revelam a resiliência de um homem Que viveu tempos de ditadura militar e de regime segregacionista e de exclusão social das colônias para tratamento da hanseníase. Veganin com sua abnegação corporal, social e emocional compõe na Via Sacra o cenário do seu cotidiano com cores e traços fiéis à realidade da hanseníase e do seu tratamento, assim seu Quadro é um convite a refletir sobre o estigma, preconceito e imaginário social da doença.

Na sua Via Sacra vemos a arte representando plasticamente a realidade histórica da hanseníase. Ao longo da história, "lepra e leprosos" foram objetos de representações de caráter depreciativo Que permitiam a utilização do modelo de tratamento para a doença fundamentado na exclusão do doente e no seu confinamento compulsório em instituições asilares.

Mas a singularidade da leitura crítica e profunda acerca da doença e da Colônia realizada por Veganin corre risco, pois os Quadros que se encontram no interior da Matriz Santa Isabel apresentam a pintura em estado de deterioração necessitando de restauração por ser patrimônio material e cultural da comunidade Betinense e da memória da hanseníase e da Enfermagem.

\section{REFERÊNCIAS}

1. Matos DM, Fornazari SK. A lepra no Brasil: representações de poder. Cad Ética Filosofia Política 2005; 6(1): 45-57.

2. Oliveira MHP, Romanelli G. Os efeitos da hanseníase em homens e mulheres: um estudo de gênero. Cad Saúde Pública 1998; 14(1): 5 1-60.

3. Araujo MG. Hanseníase no Brasil. Rev Soc Bras Med Trop 2003; 36(3): 373-82.

4. Gil AC. Métodos e técnicas de pesquisa social. São Paulo: Atlas; 1999.

5. Frochtengarten F. A memória oral no mundo contemporâneo. Est Avançados 2005; 19(55): 367-76.

6. Panofsky E. Significado das artes visuais São Paulo: Ed. Perspectiva; 1991.

7. MORHAN. Movimento de reintegração de pessoas atingidas pela Hanseníase. Colônia Santa Isabel: do estigma à socialização. Betim (MG): MORHAN; 2006.

8. Goffman E. Manicômios, prisões e conventos. São Paulo: Perspectiva; 1961.

9. Gusmão APB. A história dos trabalhadores de enfermagem exhansenianos da Colônia Santa Isabel em Betim, Minas Gerais [monografia]. Betim (MG): Escola de Enfermagem, Pontifícia Universidade Católica de Minas Gerais; 2007.

10. Silva CS. A frustração narcísica dos atendentes de enfermagem. In: Gonçalves BD, Guerra AMC, Moreira JO, organizadores. Clínica e inclusão social: repensando a subjetividade e a intervenção clínica em psicologia. Belo Horizonte (MG): Campo Social; 2002. p. $141-8$.

11. Costa MM. Dossiê de tombamento do portal da Colônia Santa
Isabel: Nova Via Sacra na Matriz. Betim (MG); 1992.

12. Reesink UFM. Carta: Leprosário de Betim, Minas Gerais, Brasil. Betim (MG); 1988.

13. Octaviani A. Cristo em pleno caos social - hanseniano dá nova versão para Via Sacra. Jornal do Brasil 1993 abr I; 3(9).

14. Bóros LF. Detecção de depósitos mínimos de substância amilóide em pacientes portadores de hanseníase virchoviana: estudo comparativo de 20 necropsias [dissertação]. Bauru (SP): Faculdade de Odontologia, Universidade de São Paulo; 1986.

15. Martins SR, Imbroisi MH. POP-Art. [citado em: I 8 maio 2008]. Disponível em: http://www.historiadaarte.com.br

16. Pronzato A. A via-sacra de todos nós. Porto: Editorial Perpétuo Socorro; 1972.

17. Boff L. Via-sacra da ressureição: a paixão, a morte e a ressurreição na vida de cada pessoa. Petrópolis: Vozes; 1983.

18. Claro LBL. Hanseníase: representações sobre a doença. Rio de Janeiro: Editora Fiocruz; 1995.

19. Oliveira MLW, Mendes CM, Tardin RT, Cunha MD, Arruda A. A representação social da hanseníase, trinta anos após a substituição da terminologia "lepra” no Brasil. Hist Ciênc SaúdeManguinhos 2003; 10 (sup 1): 4I-8.

20. Diniz O. Também somos gente: trinta anos entre leprosos. Rio de Janeiro: Livraria São José; 1961.

21. Chagas RC. História da Colônia Santa Isabel. [citado em: 15 junho 2008]. Disponível em: http://www.betim.org/jornal

22. Barlach L. O que é resiliência humana? Uma contribuição para a construção do conceito. [dissertação]. São Paulo (SP): Instituto de Psicologia, Universidade de São Paulo; 2005. 